\title{
Zur Geschichte der Naturwissenschaften
}





\section{ABHANDLUNGEN UND VORTRÄGE}

ZUR GESCHICHTE DER

\section{NATURWISSENSCHAFTEN}

VON

\section{PROF. DR. EDMUND O. VON LIPPMANN}

DIREKTOR DER "ZUCKERRAFFINERIE HALLE“

ZU HALLE a. S.

"Die Geschichte der Wissenschaft ist die

Wissenschaft selbst." Goethe.

VERLAG VON VEIT \& COMP. IN LEIPZIG

1906 
Druck von Fr. Richter in Leipzig. 
HERRN GEHEIMRAT

\section{PROFESSOR DR. EMIL FISCHER}

IN DANKBARKEIT UND VEREHRUNG

GEWIDMET 
